\title{
The Study OF Mixing IN THE OCEAN: A BRIEF HISTORY
}

\begin{abstract}
Origins
Between the mid 1950s and the 1970s, new technology permitted measurements of centimeterscale variability in the ocean. By directly observing the scales at which viscous and diffusive dissipation complete the action of turbulent mixing, oceanographers were finally able to test centuries-old ideas and develop new concepts based on such measurements. As pointed out by Garrett (1983), mixing of the ocean is now approached in three ways: by inferences about the underlying causes of large-scale behavior; by measurements of the small scales at which mixing occurs; and by process studies conducted in laboratory tanks and with theoretical models. Before the $1960 \mathrm{~s}$, inferences played the major role, as turbulence could not be measured in places less energetic than tidal channels and too little was known for realistic process studies. And so this brief history begins with the inferences.
\end{abstract}

\section{Inferences}

The ocean as a dissipative medium is an old idea, rich in scientific controversy. Munk and MacDonald (1960) review the major thrusts. In 1754 Kant proposed tidal friction as the source of discrepancies observed in motions of the moon and the sun. The issue remained unresolved until G. I. Taylor (1919) used current-meter measurements to estimate tidal dissipation in the Irish Sea as 5-6 $\times 10^{10} \mathrm{~W}$. Then Jeffreys (1921) and Heiskanen (1921) calculated the global tidal dissipation as $1-$ $2 \times 10^{12} \mathrm{~W}$. Later Munk and MacDonald (1960) increased this to $3.5 \times 10^{12} \mathrm{~W}$.

If tidal dissipation occurs mostly on the continental shelves, as Jeffreys believed, the average rate of viscous dissipation, $\epsilon$, in shelf water is about 1 $\mathrm{mW} \mathrm{m}{ }^{-3}$. Munk and MacDonald concluded. however, that only $\frac{1}{3}$ of the total dissipation occurs in shallow seas and speculated that the remaining energy is converted from surface tides into internal waves, which can break deep in the thermocline. Evaluating the conversion of tides into internal waves, Cox and Sandstrom (1962) found the effciency very uncertain- $9 \%$ to $69 \%$. If the efficiency is high. the average dissipation rate in the thermocline of the open ocean would be about $1 \mu \mathrm{W}$ $\mathrm{m}^{-3}$, akin to dissipating the heat of a $100-\mathrm{W}$ light bulb in a cube of water $500 \mathrm{~m}$ on a side.

Molecular viscosity and diffusion along mean gradients are much too slow to account for observed large-scale changes. Ekman (1905) developed a theoretical model to explain Nansen's observation (from the Fram) that ice drifted $20-40^{\circ}$ to the right of the wind, not downwind as previously thought. To obtain a realistic depth scale for the near-surface current spiral he calculated, Ekman was forced to assume a much larger vertical viscosity than is accounted for by the molecular viscosity of water. He

Michael C. Gregg. School of Oceanography and Applied Physics Laboratory, College of Ocean and Fishery Sciences, University of Washington, Seattle, WA 98105.

\section{By Michael C. Gregg}

took turbulent transport to be analogous to molecular diffusion, only much more intense. Therefore, the vertical flux of horizontal momentum was represented as

$$
\mathrm{J}_{\mathbf{x}}^{\mathrm{m}}=-\mathrm{K}_{\mathrm{m}} \partial \mathrm{U} / \partial \mathbf{z}
$$

with $K_{m}$ the turbulent eddy viscosity and $\partial U / \partial z$ the average vertical shear.

Unlike molecular viscosities, eddy coefficients are functions of the flow regime, as well as of the fluid. Consequently, mixing studies during the 60 years following Ekman focused on inferring eddy coefficients from observed property distributions. For example, on page 91 of The Oceans Sverdrup et al. (1942) state that:

The eddy viscosity can be determined only by examination of the effect on the mean motion. . . The corresponding [vertical] eddy viscosity has been found to vary between $I$ and 1000 c.g.s. units, thus being one thousand to one million times greater than the molecular viscosity of water. In the case of lateral turbulence the effective exchange of masses is due to the existence of large quasi-horizontal eddies. The corresponding eddy viscosity depends upon dimensions of the system under consideration and has been found to vary between $10^{6}$ and $10^{8}$ c.g.s. units.

Twenty years later a review of oceanic turbulence quoted these same values as the only quantitative information about turbulent transport (Bowden, 1962).

The cruise of HMS Challenger in the 1870s and later observations demonstrated that deep water is formed only at high latitudes, implying upwelling somewhere in the interior. The smooth and nearly exponential shape of the thermocline suggests a simple balance of the upwelling velocity, $w$, and the vertical eddy diffusivity of heat, $K_{h}$ :

$$
w \partial \overline{\mathrm{T}} / \partial z=K_{h} \partial^{2} \overline{\mathrm{T}} / \partial z^{2}
$$

The solution is an exponential; that is,

$$
\overline{\mathrm{T}} \propto \overline{\mathrm{T}}_{0} \mathrm{e}^{-\mathbf{z} / \mathrm{H}}
$$

where $\mathrm{H} \equiv \mathrm{K}_{\mathrm{h}} / \mathrm{w} \approx 1000 \mathrm{~m}$ is the scale depth of the thermocline. As discussed in Abyssal Recipes (Munk. 1966), the rate at which bottom water is formed suggests $w \approx 1 \mathrm{~mm}$ day $^{-1}$, giving $K_{h}=1$ $\times 10^{-4} \mathrm{~m}^{2} \mathrm{~s}^{-1}$, equivalent to 1 c.g.s.

An eddy coefficient of $K_{h}=1 \times 10^{-4} \mathrm{~m}^{2} \mathrm{~s}^{-1}$ requires vigorous mixing throughout the thermocline, which in most places could only be driven by breaking internal waves. Assuming that a vertical thickness $\Delta \mathrm{z}$ is homogenized every stability period, $2 \pi / \mathrm{N}$ ( $\mathrm{N}$ is the buoyancy frequency),

$$
\mathrm{K}_{\mathrm{h}} \approx \frac{(\Delta \mathrm{z})^{2}}{(2 \pi / \mathrm{N})} \quad\left[\mathrm{m}^{2} \mathrm{~s}^{-1}\right]
$$

Using $K_{h}=1 \times 10^{-4} \mathrm{~m}^{2} \mathrm{~s}^{-1}$ gives $\Delta z=0.35 \mathrm{~m}$ in the upper thermocline, where $N$ corresponds to about 3 cycles per hour. Much of the observational work in later years has been an attempt to determine whether this inference of relatively strong mixing and frequent overturning is correct. Munk's balance is not a unique solution of the thermocline problem. and alternate approaches can be constructed with no vertical mixing (Welander, 1959).

\section{Measurements}

Because measurement of fluctuations over wavelengths from meters to centimeters required extensive technological development. and hence generous funding, the initial work was motivated by Navy interest in antisubmarine warfare (ASW), acoustic and nonacoustic. Liebermann (1951). working at the Marine Physical Laboratory (MPL) of Scripps, mounted a small thermistor on the bow of a submarine to measure temperature fluctuations as small as $10 \mathrm{~cm}$. The autocorrelation function had an $\mathrm{e}^{-1}$ scale of $0.6 \mathrm{~m}$ and was used for many years to characterize small-scale thermal variability in calculations of acoustic scattering, usually with the assumption that Liebermann's measurement was a one-dimensional cut through an isotropic field.

In the summer of 1959 Liebermann chaired a Navy summer study, Project Sorrento, to assess methods of nonacoustic submarine detection (Liebermann, personal communication). Participants included British scientists G. I. Taylor, George Batchelor, and Thomas Gold, as well as Robert Stewart, who was working for the Canadian Navy at the time. Subsequently, the Applied Oceanography Group was established at MPL to make atsea measurements for testing theoretical predictions in the Sorrento report. Projects with similar motivation were done elsewhere. For example, with support from the Bureau of Ordinance and the Office of Naval Research (ONR), the Applied Physics Laboratory of the University of Washington constructed the Self-Propelled Underwater Research Vehicle (SPURV), which ran under acoustic command from a surface ship (Widditsch, 1973). Temperature, and later conductivity, sensors were used to map fluctuations over wavelengths from meters to kilometers.

The first dissipation measurements, however, began in the mid fifties at the Canadian Pacific Naval Laboratory, Esquimalt, British Columbia, when Harold Grant, Anthony Moilliet, and Robert Stewart developed the technology to observe centimeter-wavelength turbulence in surface and subsurface ship wakes (Grant et al., 1959). Stewart and Grant had studied turbulence at Cambridge under Alan Townsend, George Batchelor, and G. I. Taylor. Based on his experience with laboratory turbulence, Stewart reasoned that the ocean probably had only weak internal sources of turbulence (the role of internal waves was poorly understood) and that the stratification might effectively suppress any turbulence that did occur, causing a turbulent submarine wake to stand out (R. W. Stewart, personal communication). For these measurements, the $\mathrm{Ca}$ nadian Navy's only submarine, HMCS Grilse, doubled back at the same depth to measure its own wake. Hot-film velocity probes, previously used only in fresh water, were coated with a thin layer of 
quartz to electrically insulate the platinum element from seawater. Wake signals were hard to find, indicating that the wake collapsed rapidly and afforded a poor means of finding submarines.

Grant and Stewart realized that the equipment developed to study wakes could make a major contribution to understanding high Reynolds turbulence, and they began an unclassified project funded by the Canadian Defence Research Board. The hot film probe was mounted on a paravane (named Charlie) and towed behind a surface ship (Fig. 1). Extensive vibration isolation was required, as well as a water jet to remove biological detritus. By towing Charlie in a turbulent tidal channel, Grant $e t$ al. (1959) and Grant et al. (1962) verified Kolmogoroff's (1941) prediction of a k ${ }^{-5 / 3}$ slope of the inertial subrange cutoff by viscosity at a wavenumber of $\mathrm{k}_{\mathrm{K}} \propto\left(\epsilon / v^{3}\right)^{1 / 4} \mathrm{rad} \mathrm{\textrm {m } ^ { - 1 }}$, where $\nu$ is the kinematic viscosity. The 100-m-deep channel and a 1 $\mathrm{m} \mathrm{s}^{-1}$ current provided a Reynolds number of about $10^{8}$, much larger than was obtainable in laboratories. Dissipation rates were $2-60 \mathrm{~mW} \mathrm{~m}^{-3}$, and the viscous cutoff occurred near $0.2 \mathrm{k}_{\mathrm{K}}$, or $200-600$

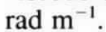

Subsequent work added a cold film that could sense centimeter-scale temperature fluctuations while moving at $1 \mathrm{~m} \mathrm{~s}^{-1}$ (Fig. 2). Returning to the tidal channel provided additional confirmation of Batchelor's (1959) prediction of a $\mathrm{k}^{-3}$ viscous-convective subrange at wavelengths smaller than the viscous cutoff of velocity fluctuations (Grant $e t$ al., 1968a). Moving offshore on Grilse, they discovered a rapid decay with depth of viscous dissipation rates-from $2.5 \mathrm{~mW} \mathrm{~m}^{-3}$ at $15 \mathrm{~m}$ in the surface mixed layer to $15 \mu \mathrm{W} \mathrm{m}{ }^{-3}$ at $90 \mathrm{~m}$ in the thermocline. Grant et al. (1968b) remarked:

The most striking conclusions from this record are that there is turbulence in the thermocline and that it is in patches.

Nasmyth (1970) followed by cycling the paravane in depth along the tow path, discovering patches several meters thick and hundreds of meters in the horizontal. The patches, dubbed "blini" (Russian for pancake), were separated by wide stretches having no signals. In some cases, patches of temperature microstructure were found with no

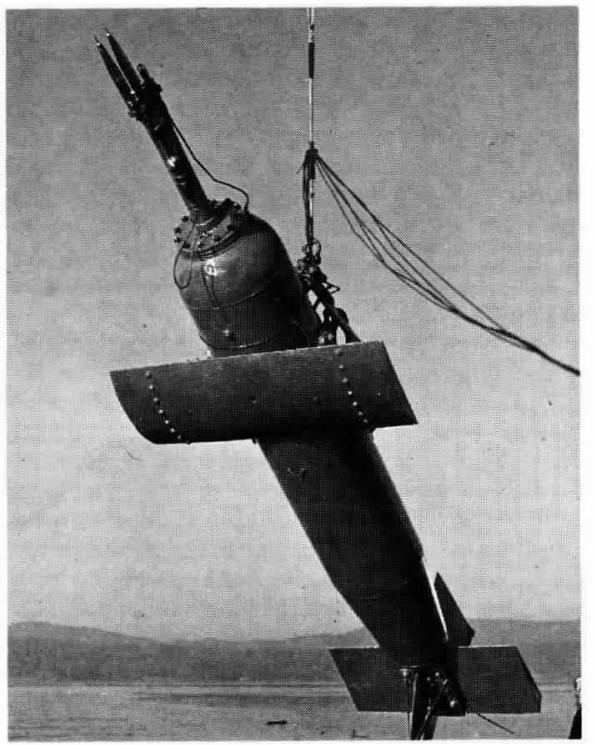

Fig. 1: Paravane Charlie seen from below. The pointed probes at the upper left are a hot film and a cold film. Just behind those two is a thermistor with a protective guard. Below these probes is a small ducted current meter for measuring Charlie's speed through the water. Fig. 2 shows these in detail.

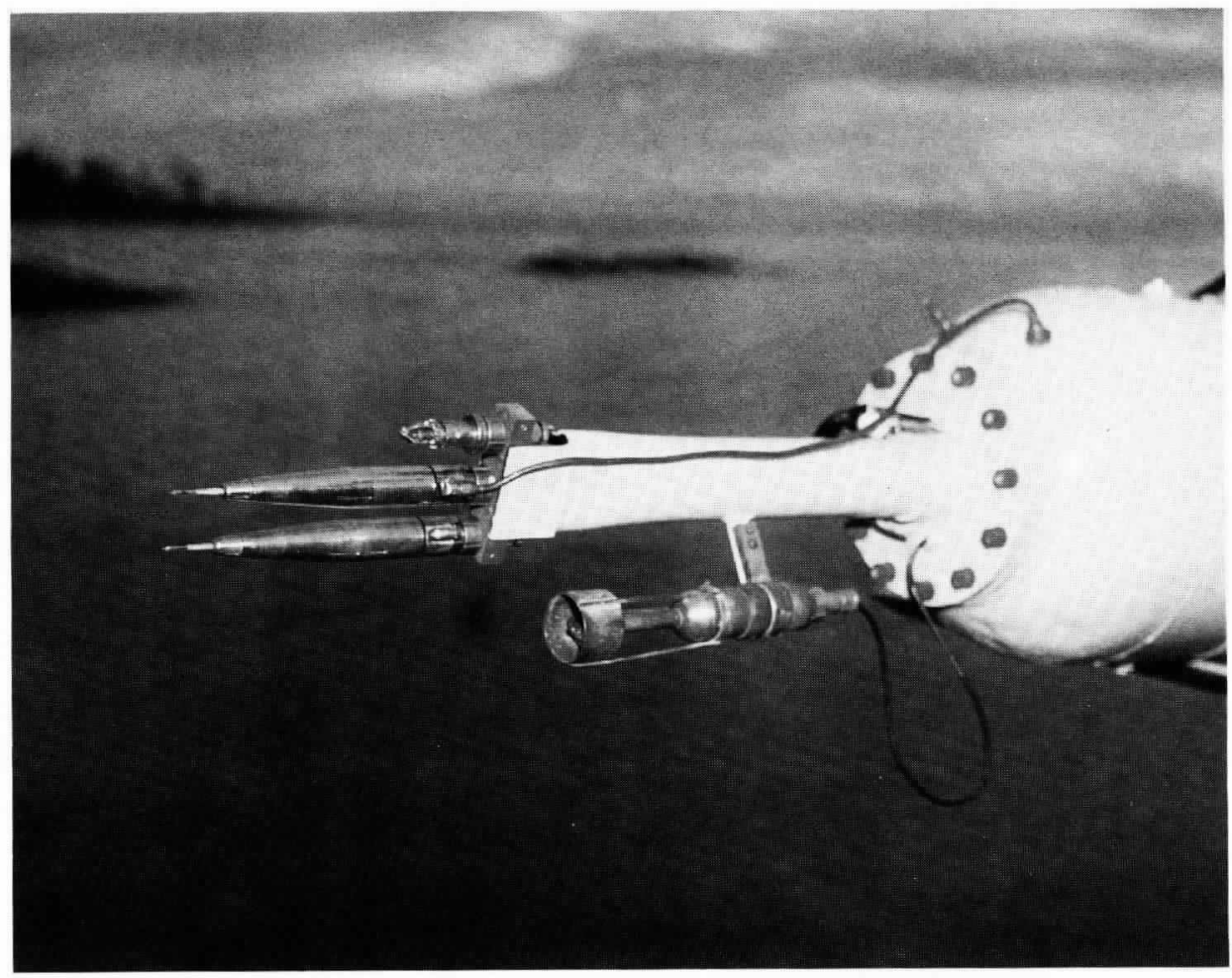

Fig. 2: Charlie's sensors. From the top, thermistor, hot film (for velocity), cold film (for temperature), and current meter. (Figs. 1 and 2 were provided by Harold Grant.)

velocity signals above the noise level of the sensors, which raised questions about the persistence of thermal fossils of previous turbulence. The offshore observations confirmed Stewart's hunch about the background levels of the thermocline, but also revealed a highly intermittent mixing structure superimposed on the background.

Continuous profiling, the other technique for measuring small scales, began in the less difficult environment of Alpine lakes. To study the thermal cycle, Schmidt (1914) sensed temperature with a bimetallic coil linked mechanically to a pen and chart paper housed in an inverted bell jar (Fig. 3). As it was lowered, compression of air in the bell jar raised a float (much like the ball in a toilet mechanism). The float in turn was linked to the roll holding the chart paper, advancing the paper as it rose. Successfully used to $60 \mathrm{~m}$, Schmidt's device revealed that temperature did not decrease smoothly but had an irregular, or step-like, structure. Resuming his work after World War I, Schmidt (1927) made the depth scale more linear by sliding the unit down a heavily weighted cable, using rollers to turn a worm screw which moved the glass slide that replaced the chart paper (Fig. 4). It descended at $0.3-0.5 \mathrm{~m} \mathrm{~s}^{-1}$ and could sense $0.05-0.5^{\circ} \mathrm{C}$ fluctuations. Walter Hacker (1933) used Schmidt's instrument to study seasonal cycles of Alpine lakes as part of his doctoral research.

C.-G. Rossby developed the "oceanograph," a device similar to Schmidt's (Rossby and Montgomery, 1935). Many years later, R. B. Montgomery (who used the oceanograph but did not participate in the development) said he had no recollection that Rossby knew of the earlier devices, although Rossby had made him read a book by Schmidt (Montgomery, personal communication). Under the shadow of World War II, an improved oceanograph became the Bathythermograph (Spilhaus, 1937) used by a generation of U.S. sailors for predicting sonar conditions. Lowered from a winch on deck, the smoked-glass slide in the BT recorded temperature fluctuations of about $10 \mathrm{~m}$ wavelength Apparently unaware of Schmidt's work, oceanog-

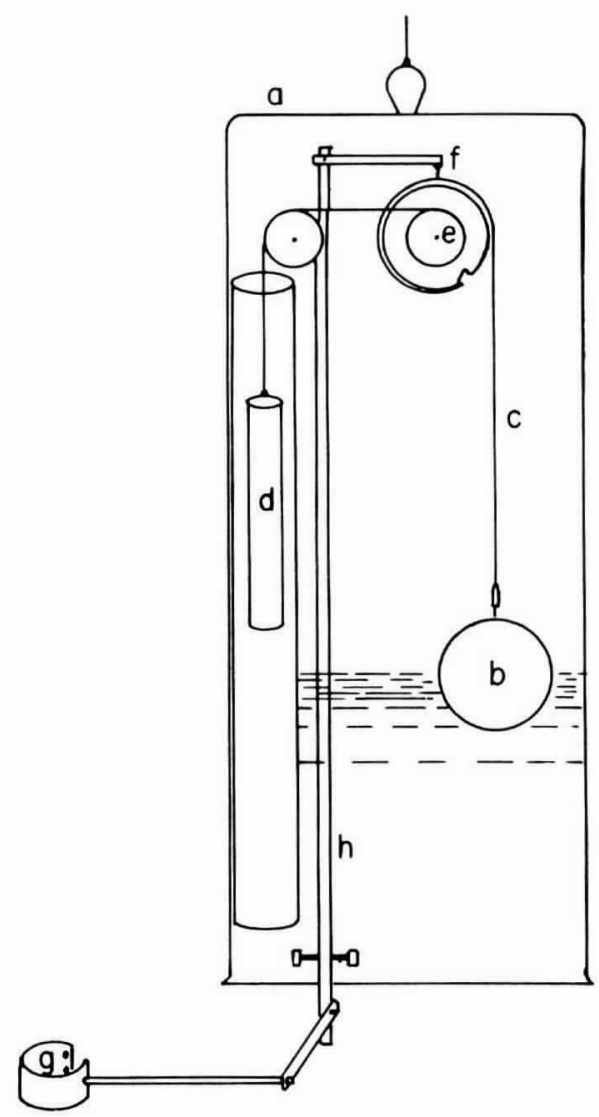

Fig. 3: Schmidt's bell-jar temperature profiler. The parts are: a) the bell jar, b) the float, c) cord, d) weight to pull the cord as the float rises, e) drum holding the chart paper, f) stylus for marking the paper, g) thermocouple, and h) mechanical linkage. 


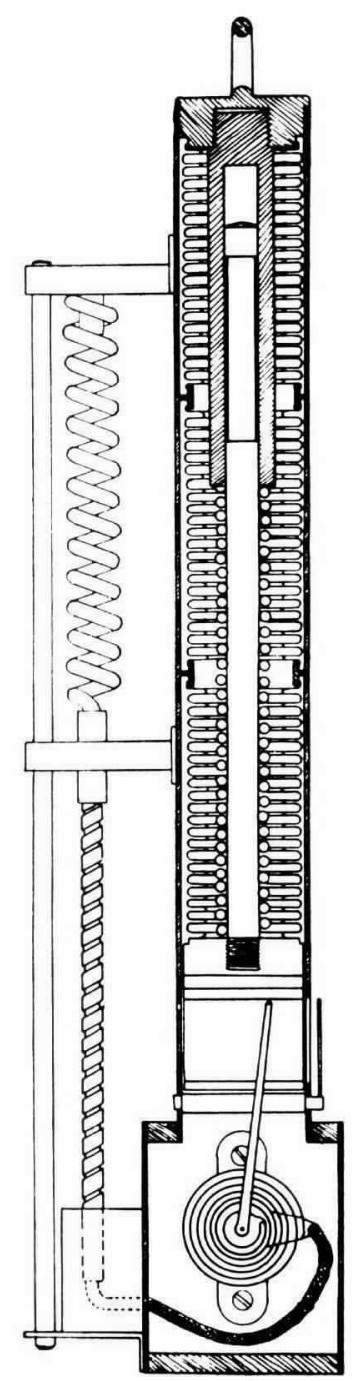

Fig. 4: Schmidt's worm drive temperature profiler. A Bourdon tube at the bottom senses temperature. deflecting the metal rod attached to the center of the tube. The glass slide is directly above the tip of the stylus.

raphers remained troubled by the sharp gradients frequently found on BT slides, and sometimes banged the BT on the deck to "fix" stiction in the mechanical linkage between sensor and slide (W. Munk, personal communication).

Electronic, wire-lowered profilers were developed after World War II but fared poorly until solidstate electronics vastly improved reliability. The first commercial salinity-temperature-depth (STD) system was sold to Scripps in 1964 by the Bissett-Berman Company. Development had begun several years before as a component of the Anti-Submarine Warfare Environmental Prediction System (ASWEPS) and the Shipboard Oceanographic Survey System (SOSS). An inductive conductivity cell and a platinum wire with a time constant of at least 1 second yielded temperature and an analog computation of salinity. Temperature resolution was limited to several meters, and the mismatch in response of the platinum wire and the inductive cell produced severe salinity "spiking," which precluded density measurements over the scales of mixing.

Using an STD off the Philippines, Stommel and Fedorov (1967) noted the step-like nature of profiles and constructed a simple mixing model based on complete mixing over vertical scales of several meters. Desiring greater vertical resolution, Stommel defined criteria for an improved STD and initiated Office of Naval Research (ONR) support at Woods Hole for Neil Brown, designer of the Bissett-Berman system. The result was a major advance; the new system recorded temperature, pressure, and conductivity as 16-bit words, allowing subsequent digital filtering to optimize the data (Brown, 1974). Although accuracy and vertical resolution were much better than those of the STD, salinity spiking and ship roll limited the data to scales larger than those of the mixing. To make the instrument available, the Navy approved Brown's founding a company, which dominated the profiling business for a decade.

Charles Cox also wanted to understand the nature and origin of thermocline layers, and he was intrigued by records from an STD forerunner constructed at Scripps by James Snodgrass (C. Cox, personal communication). Concluding that shipinduced heaving made wire-lowered instruments hopeless for turbulence measurements, in $1963 \mathrm{Cox}$ began development of the free-fall Microstructure Recorder (MSR) for measuring centimeter-scale temperature fluctuations (Fig. 5). Giving up any link to the surface, Cox risked a large fraction of his annual ONR budget with each drop, relying on fracture pins and corrodible links to drop ballast weights when the electronic release failed. He detected thermal microstructure with a 0.25 -mm-diameter glass-rod thermistor mounted on the bottom end cap (Cox et al., 1969). Although the thermistors were much slower to respond than the cold film, their large thermal sensitivity and electrical resistance (in a high-gain, high-pass circuit) resulted in a noise level less than $10 \mu^{\circ} \mathrm{C}$. By rotating with liftgenerating wing blades, the MSR fell at $0.1 \mathrm{~m} \mathrm{~s}^{-1}$, slow enough to resolve the diffusive cutoff of temperature fluctuations. Data were recording internally, first on paper charts, and later on frequencymodulated magnetic tapes.

To relate the MSR temperature records to vertical diffusivity, Osborn and Cox (1972) started with the entropy formulation of the Second Law of Thermodynamics, obtaining

$$
\mathrm{K}_{\mathrm{h}}=1 \text { to } 3 \frac{\overline{\left(\partial \mathrm{T}^{\prime} / \partial \mathrm{z}\right)^{2}}}{(\partial \overline{\mathrm{T}} / \partial \mathrm{z})^{2}} \kappa_{\mathrm{T}} \quad\left[\mathrm{m}^{2} \mathrm{~s}^{-1}\right]
$$

where $\kappa_{\mathrm{T}}$ is the molecular diffusivity, and the factor of 1 to 3 is the uncertainty in the isotropy of the temperature fluctuations. Temperature fluctuations, $\mathrm{T}^{\prime}$, created by turbulence overturning against the average gradient, $\partial \overline{\mathrm{T}} / \partial \mathrm{z}$, are assumed to be dissipated locally by the enhanced diffusion accompanying turbulence. Thus, Munk's cannonical $K_{h}$ $\approx 1000 \kappa_{\mathrm{T}}$ predicts an rms temperature gradient 30 times the mean gradient. A $25-\mathrm{m}$ record, however, found rms levels only about 10 times the mean gradient. Therefore, the formula above gives $\mathrm{K}_{\mathrm{h}} \approx 1$ $\times 10^{-5} \mathrm{~m}^{2} \mathrm{~s}^{-1}$, compared with Munk's inference of $\mathrm{K}_{\mathrm{h}} \approx 1 \times 10^{-4} \mathrm{~m}^{2} \mathrm{~s}^{-1}$. Subsequently, for my $\mathrm{Ph}$. D. dissertation we added a microscale conductivity cell (Gregg and Cox, 1971). Using a spring-loaded piston to suck water through a millimeter-diameter hole, we measured the potential drop across the hole with one pair of electrodes while another pair supplied the current. Silicone oil ejected through a small hole at the rear of the assembly controlled the flow rate through the sensing hole and electrically insulated the back path. The contraption was messy to use, frequently spewing silicone oil over the MSR, the deck, and me, but it vielded some excellent salinity data to scales of a few centimeters. Salinity spiking was minimal because a thermistor was mounted directly in front of the conductivity hole, insuring that both records sampled the same water.

Working in the mid sixties with a team of Royal Navy divers, U.K. oceanographer John Woods developed a completely different approach to mixing. by dropping dye pellets through the shallow thermocline off Malta and photographing the tracks.
Thin kinks developed rapidly, separated by much thicker undistorted sections. Realizing that the kinks occurred where density increased more rapidly than average, Woods then dyed the high-gradient regions by suspending dye packets in them. The dye spread horizontally, revealing internal waves trapped on the thin sheets. These waves sometimes broke in patterns resembling Kelvin-Helmholtz billows, much like clear-air turbulence (Woods, 1968). The major difference from the atmosphere was the small-scale of the thermocline events, typically only $0.2 \mathrm{~m}$ in the vertical. These observations led Woods to propose a "sheet and layer" model of the thermocline (Woods and Wiley, 1972) which formed the basis of much theoretical work in the seventies.

\section{Process Studies}

The rapid collapse of Grilse's wake stimulated a seminal paper about mixing in stratified fluids (Stewart, 1959) and shifted the focus of wake studies. During a second naval study, San Diego in 1961, Stewart (personal communication) recalls identifying internal-wave radiation from collapsing wakes as a mechanism that could produce a signature on the sea surface. To investigate this possibility, Stewart collaborated with Alan Schooley of the Naval Research Laboratory in running a self-propelled body down a tank. They demonstrated that the rapid wake collapse produced by buoyancy forces is indeed an efficient generator of internal waves and that the waves can cause movements at the surface (Schooley and Stewart, 1963). Their only citation is Lamb's (1932) Hydrodynamics, implying that theirs was the first laboratory study of collapsing wakes.

Schooley (1967) followed up while working temporarily at the SACLANT Undersea Research Centre in La Spezia. He reported that the collapse starts after approximately half a stability period, $0.44 \times 2 \pi \mathrm{N}^{-1}$, and that the maximum rate of horizontal spreading occurs at $2 \times 2 \pi \mathrm{N}^{-1}$. Blythe Hughes, at the Esquimalt laboratory (renamed Defense Research Establishment Pacific), continued the collaboration, producing a linear theory of the

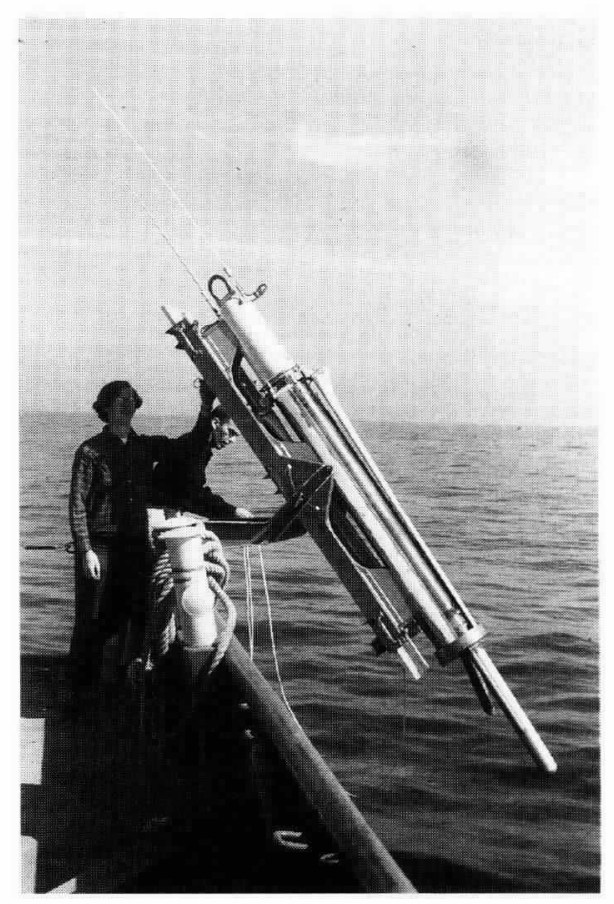

Fig. 5: The author (right) and an undergraduate helper preparing to launch Cox's MSR. A metal can holds down the wing blades and protects the probes. Just below the can is the droppable ballast weight. 
internal-wave field that became the basis of much subsequent research (Schooley and Hughes, 1972). A long sequence of laboratory and theoretical work followed, of which the most widely quoted is $\mathrm{Wu}$ (1969). based on an experiment done at the $\mathrm{Hy}$ dronautics Corporation.

Beginning about the same time, many other experimenters sought to stimulate rising atmospheric thermals, entraining cloud tops, and deepening oceanic mixed layers. For example, starting with a uniform stratification in a small tank. Turner and Kraus simulated a turbulent mixed layer by vertically oscillating a stirring grid. The analytical model that resulted (Kraus and Turner, 1967) was incorporated into theoretical and numerical models used by both academic oceanographers and those predicting sea-surface conditions for the Navy. Much of this work is reviewed by Turner (1973).

Other laboratory and numerical studies focused on Kelvin-Helmholtz billows, inspired by radar returns from overturns in the atmosphere and by Wood's photographs from the shallow oceanic thermocline. Many of these studies are reviewed by Thorpe (1973).

Before 1960 , the large contrast in the molecular diffusivities of heat and salt was not considered important in the ocean because transport was attributed to turbulence having equal eddy coefficients for the two scalars, e.g. Sverdrup et al. (1942, p. 93). Re-examination of this long-held view began with An oceanographical curiosity: The perpetual salt fountain by Stommel et al. (1956). They proposed raising nutrient-rich water through the tropical thermocline using natural convection in a copper pipe. Since the tropical thermocline is also a strong halocline, once started an upward flow in the pipe would be sustained by the buoyancy it gained from exchanging heat, but not salt, through the pipe wall. As recalled by Stommel (personal communication):

In the mid fifties. Arnold Arons and I were trying to install a Vibratron pressure gauge off Bermuda. under the thermocline, to compare the pressure there with that measured at the tide gauge at the Biostation. We couldn't get it to work-cable troubles, etc. etc. A summer or two later. while talking about alternatives, we thought of putting a hose down instead of a cable and filling it with water

we would measure the level ashore in a vertical tube. Then, we began to think about the temperature in the tube. We initially had thought of filling the tube with fresh water but water is precious on Bermuda, so we thought of seawater. Then we realized that if we sucked the seawater up to fill it from the bottom of the tube. it would be fresher than shallower water, and calculated how high it would stand ... Arons drew an open faucet below the level at which the water stood in the tube, indicating that we should then get a steady flow. He invented the salt fountain at that moment. It seemed miraculous, and one colleague (who later ran for Congress) pooh-poohed it saying that we were violating thermodynamics. So we went downstair to Duncan Blanchard, and he built a little working model of the fountain. That is why there are three authors on the Fountain paper. The essential idea of course was Arons's because he saw what would happen if the upper end of the tube was below the static level.

Taking the salt fountain seriously, Stommel tried to construct one:

Well, here I have to mention myself again. . . . It was Howard, Nergaard and me ... on the Atlantis off Martinique. We had 2000 meters of plastic tubing. The tubing was too flexible, so we couldn't raise water in it easily without having it collapse above the sea. We hadn't thought out the problem of viewing the level in the tube, over the side of the ship. with the waves running . . . you must imagine trying to see the meniscus accurately while leaning over the rail. We couldn't bring the tube into the lab as a siphon because it was too flexible. The tube was kinking constantly, even though we tried lowering it freely, and then taped it to the hydro-wire. It was a mess.

Then we thought, in desperation, that we'd let the tube float freely attached to a little styrofoam float. We saw pulsating fountain, but we decided it was probably produced by some peristaltic effect as the tube was stretched vertically by the motion of the float up and down in the waves.
We got terribly fed up with doing a lousily planned experiment: the ship had other business to do; and we cut the hose loose and let it sink off the island, much like old Georges Claude did with his huge thermal power tubes off Cuba many years before.

Meanwhile, Groves (1959) did a hydraulic analysis, estimating vertical velocities of almost 0.2 $\mathrm{m} \mathrm{s}^{-1}$ for a copper pipe $0.1 \mathrm{~m}$ in diameter and 600 $\mathrm{m}$ long. Nevertheless, Groves concluded that the nutrients brought up by one fountain would yield no more than $54 \mathrm{~kg}$ of fish per year and suggested that the same fertilization could be had more easily by dumping $290 \mathrm{~kg}$ of Peruvian guano in the surface water.

Fortunately, developments took a happier turn, as nature provides her own fountains, now known as salt fingers. Throughout the thermocline, internal waves and other motions form thin gradients of temperature and salinity. Because heat diffuses much more rapidly than does salt. the thin gradients are soon left as salinity anomalies that are out of hydrostatic balance and must sink or rise, depending on whether they are more, or less, dense than the adjacent water. When the large-scale profile has cool fresh water lying above warm saline water, the salinity anomalies act to inhibit thermal convection, forming a series of step-like interfaces. For want of a better name, this is called the diffusive regime. The transition in thinking from the salt fountain to salt fingers is a fascinating story of discovery. Again from Stommel:

In 1960 Melvin Stern and I were standing at the blackboard in my office at Bigelow. We were trying to find some configuration of water masses that would use the difference of diffusivity and conductivity to stimulate convection. Melvin had the inspiration of introducing salt formally into the Rayleigh convection problem. That ought to have occurred to me, since I had previously worked with the Ravleigh problem. But Melvin did it first, there on the blackboard. My immediate reaction was that the process should be fine grained, not the large Rayleigh cells, so while Melvin worked out the Rayleigh problem with salt and heat on the board. I went across the hall to William Malkus. who immediately produced the theory of steady-state salt fingers. Meantime. Allan Faller had come in and produced some crude fingers in the sink.

That is my recollection. Perhaps there are other views of that frantic two or three hours.

The Turner business [development of the diffusive regime of double diffusion] was calmer. 1 was still trying to explore a little beyond the formal Rayleigh problem, and talked with Turner about other configurations. We dreamed up the layer forming problem, and performed the first experiment in a cylinder left over night on a radiator.

A graduate student, Bruce Magnell. made a valiant, if unconvincing, effort to detect salt fingers with a microprobe towed through the water. Alden Winn, a professor from the University of New Hampshire, was then building a submersible measurement vehicle at WHOI. Sandy Williams added optical measurements to detect salt fingers.

I hope that this gives some idea of the confusion, excitement, and multi-personal nature of the earlier history of salt fingers. It developed as a result of the collisions among several types of mind with varying degrees of mathematical and physical insight. I think that it could not have occurred without the free and open excitement that the ideas evoked from the various players. We all enjoyed the experience, and the free exchange of ideas that occurred.

Following Stern's (1960) analysis of the Rayleigh problem for double diffusion, Stewart Turner at Cambridge began a very productive series of experiments funded by the British Admiralty, with summer grants from the National Science Foundation for work at Woods Hole. The oceanographic relevance was soon provided by Tait and Howe (1968). Using a Hytech STD west of Gibraltar, they discovered a temperature-salinity staircase with layers $15-30 \mathrm{~m}$ thick in the tongue of saline water exiting the Mediterranean. Staircases are rare, and laboratory experiments at Woods Hole during the summer of ' 68 soon demonstrated that salt fingers in linear gradients drive larger-scale convection in a sequence of stairstep layers (Stern and Turner, 1969).
Another class of instability with possible application to the ocean-the viscous-diffusive instability of geostrophic shear-was studied theoretically by McIntyre (1970) and in the laboratory by Baker (1971) and Calman (1977). This instability transports momentum primarily and can occur when the stratification is too strong for shear instability. It may be the cause of some layered structures reported in the ocean, but sufficiently detailed measurements have not been made to be certain.

\section{Growth}

The study of small-scale processes, already established as a promising field, grew rapidly in the 1970 s, spurred jointly by scientific and naval needs. Arguments such as Munk's Abyssal Recipes held that small-scale mixing controlled major aspects of the large-scale structure, e.g. the shape of the thermocline. There was a widespread interest, therefore, in replacing inferences of eddy coefficients with direct measurements of mixing. In spite of Stewart's conclusion about finding wakes, increasing reliance on ballistic-missile submarines as the most secure leg of the U.S. strategic triad-bombers. missiles in silos, and missiles in submarines-made it imperative to understand all aspects of the threat posed by wakes. Unlike many other signatures, wakes cannot be eliminated and remain behind, reducing the area that must be searched to determine whether a submarine is in the vicinity. The naval problem was studied at applied laboratories, such as the $\mathrm{Na}$ val Research Laboratory (NRL) and the Applied Physics Laboratory of Johns Hopkins University (APL/JHU), in addition to innumerable consulting firms. Studying the background was fostered at academic institutions, mostly by ONR acting in direct response to the wake problem. At the time, the NSF program managers viewed small scales as an ONR problem and were not receptive to proposals. In addition to the basic research (6.1 funding in DoD parlance), a growing realization that wake detection was a signal-to-noise problem led the Navy to establish the Ocean Measurements Program in the Oceanographer's Office. Some of these 6.3 funds were assigned to the Naval Ocean Research and Development Activity (NORDA) to develop instrumentation suitable for use by NAVOCEANO. In about 1978. Jim O'Brien and Stan Wilson, ONR program managers for physical oceanography, put their microstructure investigators in contact with Ken Ferer, who managed OMP instrument development at NORDA. This led to development of many of the instruments used today by both academic and applied communities. Expendable probes, especially from aircraft, were a special focus. Following the steep rise in ship costs after the 1973 Arab oil embargo, ONR program managers viewed expendables as necessary for continuing to make measurements at sea.

\section{Instrumentation}

Among the many early attempts at measuring the ocean's smallest scales, the submarine and towed body work in Canada and Cox's free-fall profiles established the direction for future efforts. The initial thrusts were development of better sensors and vehicles and understanding the response of existing sensors. This phase was largely driven by young investigators trained as experimental physical oceanographers, particularly by Cox. One, P. Hacker, made measurements in Lake Tahoe as part of his dissertation (1973), forty years after his father completed work with Schmidt (W. Hacker, 1933).

In the early seventies Chip Cox began the design of a more capable microstructure profiler while I used the original MSR at sea. At the same time. two students of Walter Munk adapted Snodgrass's seafloor tide capsules to mid-water depth-cycling platforms for observing internal waves and thermal microstructure (Cairns and Williams, 1976). All of us were supported by the Defense Advanced Research Projects Agency (DARPA). 
Also at Scripps, Carl Gibson, with an extensive background in laboratory turbulence, developed a sequence of towed bodies. From the shape of temperature spectra obtained by towing a heavy, upright cylinder. Williams and Gibson (1974) inferred very high dissipation rates in the core of the equatorial undercurrent, confirming earlier Soviet measurements. Because these rates seemed too high based on energetic arguments and have not been confirmed by profiling measurements. most western. and some Soviet, investigators have attributed them to vibration of the towed body. Gibson continues to disagree (Gibson, 1983). A later streamlined body was designed by the Navy laboratory in Panama City, Florida, under the sponsorship of APL/JHU (Washburn and Gibson, 1984).

Tom Osborn, Cox's first microstructure student. became a professor at the University of British Columbia about 1970 and built several free-fall vehicles, one of which was designed by a committee and called Camel. With ONR funding, he also developed the airfoil turbulent velocity sensor for use in the ocean (Osborn, 1974). The airfoil probe was originally invented for use in wind tunnels by a professor of Mechanical Engineering at UBC (Siddon, 1971). (Siddon later was elected to the Canadian parliament and became Minister for Fisheries and Oceans in the Mulroney cabinet.) The combination of weak turbulence and strong temperature fluctuations make the hot film unsuitable for the thermocline: the airfoil has replaced it as the standard for oceanic use. With NORDA funding, the airfoil was attached to an XBT assembly, making an expendable dissipation profiler (Lueck and Osborn, 1981). Continuing the development at the Naval Postgraduate School, Osborn and Lueck (1985a) reported successful slow-speed towed measurements of airfoil probes mounted on a sur plus aircraft fuel tank, used as a streamlined body. This work was supported by NORDA and the Postgraduate School. At the instigation of Stan Wilson of ONR, Osborn also began measurements from the Navy's research submarine, USS Dolphin (Osborn and Lueck, 1985b)

By the seventies, Robert Stewart had become director of a new Environment Canada laboratory at Patricia Bay outside Victoria and arranged to transfer the turbulence project from the Defence Research Establishment Pacific. When the laboratory received a manned submersible, he decided to use it for turbulence research. Built in Vancouver, the Pisces had been ordered by the Soviets. The sale was blocked by the U.S., citing use of American equipment in manufacturing the pressure hull, and the Canadian cabinet assigned it to Stewart's laboratory. Osborn, on sabbatical, played an important role in developing the turbulence instrumentation. and Ann Gargett became the major investigator for the turbulence measurements. Used in local waters for safety, the Pisces was able to measure all three components of turbulent velocity (Gargett et al. 1984). The airfoils, which measure fluctuations perpendicular to their axes, were oriented to sense vertical and horizontal motions transverse to the forward speed of the craft. Weak temperature stratfication in local inlets allowed the use of a hot film to sense fluctuations along the direction of motion Gargett's enthusiasm for this submersible ended when she saw a fitting, capable of sinking it, easily knocked off on deck. No further turbulence work was done with the Pisces.

In 1970 Jim Elliott, Bob Stewart's last graduate student at UBC, started work at the Bedford Institute of Oceanography, near Halifax. Whereas the West Coast Canadian group was still seeking highReynolds-number turbulence in the ocean, Elliott sought representative turbulence levels and how they relate to the larger-scale environment. Wanting to take multiple profiles to form representative averages, he teamed up with another new employee. Neil Oakey, who had a Ph.D. in experimental physics from Texas A \& M. They built a relatively large instrument that was suspended on $\frac{1}{4}$-inch steel cable below several floats as it descended. This ar rangement decoupled the descent sufficiently from the heaving of the ship to let them measure thermal microstructure with arrays of four cold films and a thermistor. Their initial efforts were to survey the Gulf Stream in 1972 (Oakey and Elliott. 1977) and the Denmark Strait in 1973 (Oakey and Elliott. 1980a). In 1973 they purchased several of Osborn's shear probes from Thermosystems, but found the probes faulty and their instrument vibrating badly (Oakey, 1977). Dropping the floats, they built OCTOPROBE II with an internal tape recorder and a parachute cord tether. In 1974 it was used in the tropical Atlantic during the GARP Atlantic Tropical Experiment (GATE).

Douglas Caldwell, at Oregon State, also developed tethered profilers, first for use in lakes and then on the Oregon shelf and in the open ocean. NASA and ONR supported those developments. One version could release a weight and make an upward profile, to observe the near-surface zone free of the launch transients experienced with standard downward profilers. The OSU profilers are lightweight, originally having potted electronics to avoid using a pressure case. A later version is operated from the stern while under way, permitting synoptic sections (Caldwell et al., 1985). The microstructure observations, about one cast per kilometer, are complemented by continuous temperature sections taken at the same time with the thermistor chain developed by Clayton Paulson.

In 1974 I went to APL-UW, taking Cox's original MSR - which had been badly beaten up by the propellor of the R/V Washington on my last cruise with Scripps. Rebuilt as a digital system, it was used for several major cruises in the seventies. In 1979 , NORDA funded us to use the MSR in Puget Sound and Lake Washington with Marshall Orr's suite of high-frequency acoustic-backscatter transducers. We were trying to evaluate the correlation between thermal microstructure and the layers of intense backscatter. Watching the rapidly evolving motions in the sound, I concluded that only a tethered profiler was suitable for studying the evolution of the features. NORDA, as part of the Ocean Measurements Program, funded design and construction of the Advanced Microstructure Profiler (AMP) for use by NAVOCEANO and NORDA in taking microstructure profiles in areas of interest to the Navy. The major innovation was a fiber optic data link in the Kevlar tether, to provide a high data rate. Because this was a second generation microstructure instrument, we were able to design the electronics carefully and to make the data processing an integral part of the system (Gregg et al. 1982) Neil Oakey spent a year with us in the early eighties, showing us how to build airfoil probes; his notes are now widely used by many investigators building shear probes.

On the East Coast, Stommel had an MIT graduate student develop a towed body with a smallscale conductivity probe to search for salt fingers Although it was successfully used on one cruise (Magnell, 1976), development was not continued. However, Sandy Williams, an optical physicist working at Woods Hole, developed a shadowgraph for detecting the unique centimeter-scale banded structure of salt fingers. The Self-Imaging Microstructure Profiler (SCIMP) (Williams, 1974) found the signatures expected.

Closely coupled with the development of $\mathrm{mi}$ crostructure sensors were parallel efforts to obtain continuous shear profiles over the scales causing mixing events. Tom Sanford, at Woods Hole, developed the Electromagnetic Velocity Profiler (EMVP) to measure the electric field induced by the ions in seawater moving through the earth's magnetic field (Sanford et al., 1978). It could detect velocity fluctuations of $10 \mathrm{~mm} \mathrm{~s}^{-1}$ over vertical separations of $10 \mathrm{~m}$. To make the technology more available, ONR and then NORDA, via the Ocean
Measurements Program, funded development of the Expendable Current Profiler (XCP; Sanford $" t$ al., 1982). Now made commercially by Sippican. the XCP is used widely by academic and naval oceanographers.

Different approaches to shear profiling were begun in the United Kingdom by John Simpson (1972), who measured the deflection of a paddle mounted on the bottom of a free-fall tube called PROTAS. T. Gytre, at the Christian Michelsen Institute in Bergen. Norway, initiated acoustic traveltime current meters, one of which was mounted on a free-fall STD developed by Tom Rossby at the University of Rhode Island and called Yvette (Evans et al., 1979). Unlike the electromagnetic technique, only the current relative to the tube is measured. The signal is thus strongly affected by response of the vehicle to shear having scales larger than the tube. Evans et al. developed a transfer function that corrects for the tube response, which works well. A larger instrument with a Neil Brown CTD and acoustic current meter was developed by Stan Hayes at the Pacific Marine Environmental Laboratory (PMEL) of NOAA (Hayes et al., 1984). It was widely used in the equatorial Pacific.

To relate the diverse oceanographic parameters that could be measured with the instruments then available. Tom Sanford organized a joint cruise. the Fine and Microstructure Experiment (FAME). Using the R/V Knorr in 1975, with ONR support. we made simultaneous drops with EMVP, MSR, SCIMP. Camel, Yvette, and PROTAS. Although much was learned during FAME, no believable correspondences were obtained between shear profiles and microstructure. Calibration errors in temperature and pressure sensors and the differences in fall rate apparently produced differences that were larger than the scales of the structures. Thus, when Tom Sanford came to APL-UW in 1980, he and developed the Multi-Scale Profiler (MSP), combining shear, CTD, and microstructure sensors on one vehicle. It was funded under the ONR Research Option in Fine and Microstructure Research. Several years later ONR also funded John Toole and Ray Schmitt at Woods Hole to build a similar instrument. By that time some of the sensors were available from Sea-Bird Electronics, a firm founded by Art Pederson, who had redesigned the MSR.

Aside from Simpson's profiler and the Soviet work, measuring microstructure and shear has been mostly a North American endeavor. The instruments mentioned constitute the major activity reported in the refereed literature. Some information has also come out about systems developed at the applied laboratories, e.g.. the very sophisticated towed chain developed by Gene Rudd at NRI (Dugan et al. 1980). More recently, Australians have entered the picture, e.g., Carter and Imberger (1986).

\section{Observations}

Many initial observations with the new instruments were made in local waters and yielded useful data only some of the time. Published results were based on small data sets of 5 to 15 profiles. and were focused on the average levels and on the in ternal structure of the data. Observations farther from home were usually done alone, with only standard weather observations in the ship's log or CTD casts for background. This approach defined the vertical temperature spectrum (Gregg et al. 1973: Gregg, 1977) and discovered rms gradients in the mid-gyre thermocline that averaged only twice the mean gradient. Averages 10 times the mean gradient in winter suggested either a seasonal influence or the effect of mesoscale eddies. Whether thermal microstructure was observed in salt-stabilized temperature inversions or in monotonic thermoclines was soon found to make a major difference in level (Gregg, 1975; Gargett, 1976), demonstrating that mixing observations can only be interpreted with careful attention to the background ocean- 
ography. Dissipation levels proved to average $1 \mu \mathrm{W}$ $\mathrm{m}^{-3}$ in the upper thermocline (Gargett and Osborn, 1981: Gargett and Holloway, 1984). As expected from scaling arguments, mixed-layer dissipation rates were found to vary as the cube of the wind speed (Oakey and Elliott, 1980b).

Although the initial phase of measurements produced the basic description of the levels and wavenumber structure of mixing, too little was known about the larger structures to determine what was producing the mixing, how it evolved, and what effect it had on larger scales. Reliable instruments carrying several sensor systems were required to sustain operations in multi-investigator expeditions. Following FAME more mixing studies were conducted jointly. Some were designed around mixing in specific regimes: The Mixed Layer Experiment (MILE) was promoted by ONR in August 1977 to observe the initial deepening of the seasonal mixed layer at Ocean Station Papa $\left(50^{\circ} \mathrm{N}, 145^{\circ} \mathrm{W}\right)$, and the Joint Air-Sea Interaction Experiment (JASIN) was organized by the Royal Society of London for intensive mixed layer studies in the Rockall Trough during July and August 1978. Sometimes, to take advantage of the background information, mixing observations were added to experiments planned solely to study large scales. GATE and POLYMODE are early examples.

\section{Where Do We Stand Now? \\ -A Personal View}

Within fifteen years-from Bowden's (1962) survey of turbulence in Volume I of The Sea to the Mixed Layer Experiment (MILE) in 1977-our knowledge of mixing in the ocean was transformed from solely inferences to include measurements and process studies. Near the end of this interval, Garrett and Munk's (1972) model of internal waves and Turner's laboratory experiments provided a rudimentary framework for relating the microstructure observations to the processes producing the mixing.

The first results, summarized by Garrett (1984), show weak mixing in the upper thermocline. with $\mathrm{K}_{\mathrm{h}} \approx 10^{-5} \mathrm{~m}^{2} \mathrm{~s}^{-1}$. In keeping with this view. when internal waves are at the level of the Garrett and Munk spectrum for internal waves, the average dissipation is less than $10 \%$ of the level expected for the tidal conversion hypothesized by Munk and MacDonald (1960). Because the eddy coefficients inferred from microstructure measurements are an order of magnitude below values predicted in Munk's Abyssal Recipes and several below those supposed by Bowden and by Sverdrup et al. (1942) in The Oceans, we must question whether turbulence is a major factor in ocean dynamics. I think mixing likely can be ignored in the dynamics of large sections of the thermocline, but we will not be certain until numerical models improve sufficiently that they do not require high diffusivities to suppress numerical instabilities. We are slowly developing a sense of the geography of mixing in the thermocline and find that dissipation rates vary systematically with stratification and shear. Two major uncertainties in this view are the Southern Ocean. and the oceans under strong winter storms in the Northern Hemisphere. No observations have been made, and we may be in for some surprises.

Even if mixing plays only a little part in dynamics, it must be important on longer time scales for slow modification of water masses in the thermocline. The role of salt fingers remains a puzzle. Linear stability analyses show that much of the upper thermocline can have fingers, but neither the staircases nor the turbulent dissipation expected from laboratory experiments is found generally. Horizontal tows show what appear to be unique signatures of fingers, but, in all cases so far, these signatures are found on the boundaries of salt-stabilized temperature inversions. It may be that intrusions are important to water mass changes in mid gyre as well as in fronts and Gulf Stream rings.
Unlike the situation in the thermocline, mixing in top and bottom boundary layers has been found to be close to what was expected, even to the point of following some of the similarity scaling developed for atmospheric boundary layers (Shay and Gregg, 1986)

Finally, the rapid development of this field resulted from the interplay of many talented and eager investigators pursuing their scientific intuition in a wide variety of settings; some were funded to study submarine wakes and others were motivated only by curiosity. I doubt that such rapid progress could occur today, given the bureaucratic shift to funding projects instead of investigators and the emphasis on relevance to national goals and expected results.

\section{Acknowledgements}

While on active duty, RADM Craig Dorman requested this article and encouraged its publication. I am indebted to the following for personal recollections and/or critical review of earlier drafts: Henry Stommel, Charles Cox, James Elliott, Peter Hacker, Leonard Liebermann, R. B. Montgomery. Walter Munk, William Nierenberg. Neil Oakey, James O’Brien, and Robert Stewart.

\section{References}

Baker, D.J., 1971: Density gradients in a rotating stratified fluid: experimental evidence for a new instability. Sitence, 172, 1029-1031.

Batchelor, G.K., 1959: Small-scale variation of convected quantities like temperature in turbulent fluid. Part 1. General discussion and the case of small conductivity. Jour. Fluid Mech., 5, 113-133.

Bowden, K.F., 1962: Turbulence. In: The Sea, vol I M. N. Hill, ed., Wiley Interscience, New York, $802-825$

Brown. N.L., 1974: A precision CTD microprofiler. In: Record of OCEANS 74, vol. 2. IEEE, New York $270-278$

Cairns, J.L. and G.O. Williams, 1976: Internal wave observations from a midwater float. 2. Jour. Geophws Res., 81. 1943-1950.

Caldwell, D.R., T.M. Dillon and J.N. Moum, 1985: The rapid-sampling vertical profiler: An evaluation. Jour Atmos Oceanic Tech 2, 615-625.

Calman. J., 1977: Experiments on high Richardson number instability of a rotating stratified flow. Dyn Atmos Oceans, 1. 277-297.

Carter, GD and J. Imberger, 1986: Vertically rising microstructure profiler. Jour. Aimos Oceanic Tech. 3. 462-471

Cox. C.S.. Y. Nagata and T.R. Osborn. 1969: Oceanic fine structure and internal waves. Bull. Japan. Soc. Fish. Oceanogr. Prof. Uda Comm. Issue, 67-71. and H. Sandstrom, 1962: Coupling of internal and surface waves in water of variable depth. Jour. Ocean. Soc. Japan, 20th Anniversary volume, 499513.

Dugan, J.P., W.D. Morris, B.S. Okawa, E.E. Rudd and B.W. Stalcup, 1980: Motion stabilization for towed oceanographic sensors. Marine Technology, Proc of MTS Conf. Oct 1980, 529-534.

Ekman, V.W., 1905: On the influence of the earth's rotation on ocean-currents. Arkw for Matematik Astronom och Fisik, R. Swedish Acad. Sci, 2, 1-52.

Evans, D.L. H.T. Rossby, M. Mork and T. Gytre, 1979 . YVETTE - a free-fall shear profiler. Deep-Sea Res. 26. 703-718

Gargett, A.E., 1976: An investigation of the occurrence of oceanic turbulence with respect to finestructure Jour. Phys. Oceanogr., 6, 139-156.

and $G$. Holloway, 1984: Dissipation and diffusion by internal wave breaking. Jour. Mar. Res. $42,15-27$.

and T.R. Osborn, 1981: Small-scale shear measurements during the Fine and Microstructure Experiment (Fame). J Geophy's Res, 86, 1929 1944.

T.R. Osborn and P.W. Nasmyth, 1984: Local sotropy and the decay of turbulence in a stratified fluid. Jour Fluid Mech, 144, 231-280.

Garrett, C., 1983: Diapycnal mixing in the ocean interior. In: Proc. of the Joint Oceanographic Assembly 1982 General Assemb/y: Dalhousie University, Halifax, Nova Scotia, 19-21.

Garrett, C., 1984: Parameterizing the effects of internal waves: simple ideas and things we need to know.
In: Internal Gravity Waves and Small-Scale Turbulence, Proceedings, Hawaiian Winter Workshop. P. Müller and R. Pujalet, eds.. Hawaii Inst. of Geophys., Spec. Pub., 171-181.

and W. Munk, 1972: Space-time scales of internal waves. Geophys. Fluid Dyn. 3, 225-264.

Gibson, C.H., 1983: Turbulence in the core of the equatorial undercurrent. In: Hydrodynamics of the Equatorial Ocean. J. C. J. Nihoul. ed., Elsevier, New York, $131-153$.

Grant. H.L., A. Moilliet and R.W. Stewart, 1959: A spectrum of turbulence at very high Reynolds number. Nature, 184, 808-810.

B.A. Hughes, W.M. Vogel and A. Moilliet, 1968a: The spectrum of temperature fluctuations in turbulent flow. Jour. Fluid Mech., 34, 423-442.

R.W. Stewart and A. Moilliet, 1962: Turbulence spectra from a tidal channel. Jour. Fluid Mech., 12, 241-268.

A. Moilliet and W.M. Vogel, 1968b: Some observations of the occurrence of turbulence in and above the thermocline. Jour. Fluid Mech., 34, 443448.

Gregg, M.C., 1975: Microstructure and intrusions in the California Current. Jour. Phys. Oceanogr., 5, 253278.

1977: Variations in the intensity of small-scale mixing in the main thermocline. Jour. Phys. Oceanogr., 7, 436-454.

and C.S. Cox, 1971: Measurements of the oceanic microstructure of temperature and electrical conductivity. Deep-Sea Res., l8, 925-934.

C.S. Cox and P.W. Hacker, 1973: Vertical microstructure measurements in the central North Pacific. Jour. Phys. Oceanogr., 3, 458-469.

W.E. Nodland, E.E. Aagaard and D.H. Hirt. 1982: Use of a fiber-optic cable with a free-fall microstructure profiler. In: Record of OCEANS 82 IEEE, New York, 260-265.

Groves, G.W., 1959: Flow estimate for the perpetual salt fountain. Deep-Sea Res., 5, 209-214.

Hacker, P.W. 1973: The mixing of heat deduced from temperature finestructure measurements in the Pacific Ocean and Lake Tahoe. Ph.D. thesis, University of California, San Diego, $121 \mathrm{pp}$.

Hacker, W., 1933: Sichttiefe, Wärmegang und Durchlüftung in Hochgebirgsseen. Geogr Jahresher. Osterr. $16,88-105$

Hayes, S.P., H.B. Milburn and E.F. Ford, 1984: TOPS: a free-fall velocity and CTD profiler. Jour. Atmos. Oceanic Tech. I, 220-236.

Heiskanen, W., 1921: Uber den Einfluss der Gezeiten auf sakulare Acceleration des Mondes. Ann. Acad. Scient. Fennnnicae A, 18. 1.

Jeffreys, H., 1921: Tidal friction in shallow seas. Phil Trans Rov. Soc London, A 221. 239-264.

Kolmogoroff, A.N., 1941: The local structure of turbulence in incompressible viscous fluid for very large Reynolds numbers. Doklady Akad. Nauk. L.S.S.R., 30. 299-303.

Kraus, E.B. and J.S. Turner, 1967: A one-dimensional model of the seasonal thermocline. II. The general theory and its consequences. Tellus, 19, 98-105.

Lamb. H., 1932: Hyrodynamics Cambridge University Press, Cambridge, England, 738 pp.

Liebermann. L., 1951: The effect of temperature inhomogeneities in the ocean on the propagation of sound. Jour. Acoust. Soc. Am., 23, 563-570.

Lueck. R.G. and T.R. Osborn. 1981: Expendable dissipation profiler. In: Record of OCEANS 81, vol. I IEEE, New York, 377-381.

Magnell, B., 1976: Salt fingers observed in the Mediterranean outflow region $\left(34^{\circ} \mathrm{N}, 11^{\circ} \mathrm{W}\right)$ using a towed sensor. J. Phys. Oceanogr., 6, 511-523.

McIntyre, M.E., 1970: Diffusive destabilization of the baroclinic circular vortex. Geophys. Fl. Dyn. I 19-57.

Munk, W.H., 1966: Abyssal recipes. Deep-Sea Res., 13 707-730.

and G.J.F. MacDonald, 1960: The Rotation of the Earth: A Geophysical Discussion. Cambridge University Press, Cambridge, England, $323 \mathrm{pp}$.

Nasmyth, P.W., 1970: Oceanic turbulence. Ph.D. thesis, University of British Columbia, Vancouver, $69 \mathrm{pp}$.

Oakey, N.S. 1977: An instrument to measure oceanic turbulence and microstructure. Bedford Institute of Oceanography, Dartmouth, Nova Scotia. Report Series BI R77.

and J.A. Elliott. 1977: Vertical temperature gradient structure across the Gulf Stream. $J o u r$ Geophy's. Res. 82, 1369-1380

and J.A. Elliott, 1980a: The variability of temperature gradient microstructure observed in the 
Denmark Strait. Jour. Geophys. Res., 85, 19331944.

and J.A. Elliott, 1980b: Dissipation in the mixed layer near Emerald Basin. In: Marine Turbulence. J. C. J. Nihoul, ed., Elsevier, New York, 123-133.

Osborn, T.R., 1974: Vertical profiling of velocity microstructure. Jour. Phys. Oceanogr., 4, 109-115.

and C.S. Cox, 1972: Oceanic fine structure

Geophys. Fluid Dyn., 3, 321-345.

and R.G. Lueck, 1985a: Turbulence measurements from a towed body. Jour. Atmos. Oceanic Tech., 2, 517-527.

and R.G. Lueck, 1985b: Turbulence measurements with a submarine. Jour. Phys. Oceanogr. $15,1502-1520$

Rossby, C.-G. and R.B. Montgomery, 1935: The layer of frictional influence in wind and ocean currents. MIT Papers in Phys. Oceanogr. and Meteor., 3, $101 \mathrm{pp}$.

Sanford, T.B., R.G. Drever and J.H. Dunlap, 1978: A velocity profiler based on the principles of geomagnetic induction. Deep-Sea Res., 25, 183-210. R.G. Drever, J.H. Dunlap and E.A. D'Asaro, 1982: Design, operation and performance of an Expendable Temperature and Velocity Profiler (XTVP). Applied Physics Laboratory, University of Washington, Seattle, WA, APL-UW 8110, 169 pp.

Schmidt, W., 1914: Ein einfaches Temperaturlot. Zeitschrift für Instrumentenkunde, 34, 328-330.

, 1927: Das Wärmelot, ein Gerät zum Aufzeichnen der Tiefentemperaturen in stehendem Gewässer. Sitzungsberichten der Akademie der Wissenschaften in Wien, Mathem.-naturw. Klasse, Abteilung IIa, 136. Band, 7. Heft, 481-486. Science, 157, 421-423.

and B.A. Hughes, 1972: An experimental and theoretical study of internal waves generated by the collapse of a two-dimensional mixed region in a density gradient. Jour. Fluid Mech., 51, 159175.

and R.W. Stewart, 1963: Experiments with a self-propelled body submerged in a fluid with a vertical density gradient. Jour. Fluid Mech., 15, 83-96.

Shay, T.J. and M.C. Gregg, 1986: Convectively driven turbulent mixing in the upper ocean. Jour. Phys Oceanogr., 16, 1777-1798.

Siddon, T.E., 1971: A miniature turbulence gauge utilizing aerodynamic lift. Rev. Sci. Instr., 42, 653-656.

Simpson, J.H., 1972: A free fall probe for the measurement of velocity microstructure. Deep-Sea Res., 19, 331336.

Spilhaus, A.F., 1937: A bathythermograph. Jour. Mar. Res., I, $95-100$.

Stern, M.E., 1960: The "salt-fountain" and thermohaline convection. Tellus, 12, 172-175. and J.S. Turner, 1969: Salt fingers and convecting layers. Deep-Sea Res., 16, 497-511.

Stewart, R.W., 1959: The problem of diffusion in a stratified fluid. Adv. Geophys., 6, 303-311.

Stommel, H. and K.N. Fedorov, 1967: Small scale structure in temperature and salinity near Timor and Mindanao. Tellus, 19, 306-325.

, A.B. Arons and D. Blanchard, 1956: An oceanographical curiosity: The perpetual salt fountain. Deep-Sea Res., 3. 152-153.

Sverdrup, H.U., M.W. Johnson and R.H. Fleming, 1942: The Oceans-Their Physics, Chemistry and Gen- eral Biology. Prentice-Hall, Englewood Cliffs, NJ, $1087 \mathrm{pp}$.

Tait, R.I. and M.R. Howe, 1968: Some observations of thermo-haline stratification in the deep ocean Deep-Sea Res., 15, 275-280.

Taylor, G.I., 1919: Tidal friction in the Irish Sea. Phil Trans. Roy. Soc. London, A220, 1-33.

Thorpe, S.A., 1973: Turbulence in stably stratified fluids: A review of laboratory experiments. BoundaryLayer Meteorology, 5, 95-119.

Turner, J.S., 1973: Buoyancy Effects in Fluids. Cambridge University Press, Cambridge, England, $367 \mathrm{pp}$.

Washburn, L. and C.H. Gibson, 1984: Horizontal variability of temperature microstructure at the base of a mixed layer during MILE. Jour. Geophys. Res., $89,3507-3522$

Welander, P., 1959: An advective model of the ocean thermocline. Tellus, 11, 309-318.

Widditsch, H.R., 1973: SPURV-The first decade. Applied Physics Laboratory, University of Washington, Seattle, WA, APL-UW 7215, $37 \mathrm{pp}$.

Williams, A.J. III, 1974: Free-sinking temperature and salinity profiling for ocean microstructure studies In: Record of OCEANS 74, vol. 2. IEEE, New York, 279-283.

Williams, R.B. and C.H. Gibson, 1974: Direct measurements of turbulence in the Pacific Equatorial Undercurrent. Jour. Phys Oceanogr. 4, 104-108.

Woods, J.D., 1968: Wave-induced shear instability in the summer thermocline. Jour. Fluid Mech., 32, 791800.

and R.L. Wiley, 1972: Billow turbulence and ocean microstructure, Deep-Sea Res, 19,87-121.

Wu, J., 1969: Mixed region collapse with internal wave generation in a density-stratified medium. Jour Fluid Mech., 35, 531-544.

\section{MEETINGS AND WORKSHOPS}

\section{CO-SPONSORED BY TOS}

\section{MTS 91 in New Orleans}

The Marine Technology Society will hold a meeting during 10-14 November 1991 at the New Orleans Convention Center. For more information contact J. Spargo \& Associates, 4400 Fair Lakes Ct., Fairfax, VA 22033; fax (703) 8189172.

\section{AGU Ocean Sciences Meeting in New Orleans}

The biennial Ocean Sciences meeting of the American Geophysical Union will be held 27-31 January 1992 at the Hyatt Regency Hotel in New Orleans. Information regarding abstracts and registration can be obtained from AGU at 2000 Florida Ave, NW, Washington, DC 20009.

\section{OTHER}

\section{EEZ Symposium in Portland, OR}

The 1991 Exclusive Economic Zone Symposium will be held 5-7 November 1991 in Portland. Information regarding participation can be obtained from Millington Lockwood, JOMAR, 915 National Center, Reston, VA 22092; phone (703) 648-6525.

\section{ERF '91 in San Francisco}

The 11th biennial international conference of the Estuarine Research Federation will be held in San Francisco, 10-14 November 1991. Information and forms can be obtained from: Jerome Williams, POB 544, Crownsville, MD 21032-0544.

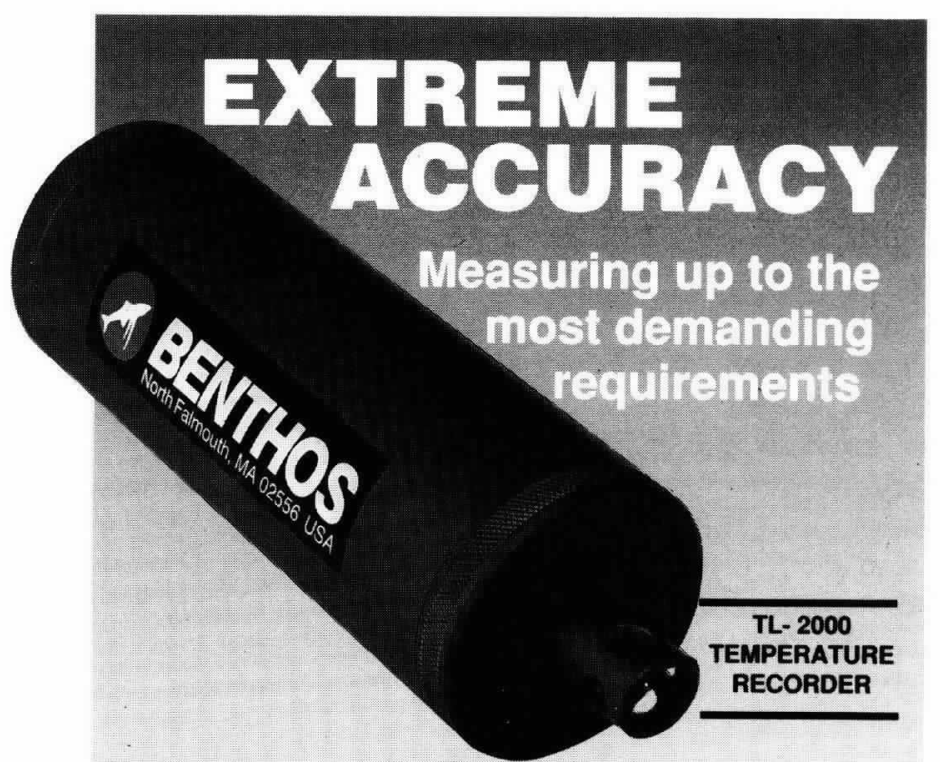

An accurate $(.020$ degrees $C)$, corrosion resistant, and easily deployable instrument for temperature recording in the marine and fresh water environment. The TL-2000 is economically priced, user-programmable, and can store up to 32,000 temperature samples.

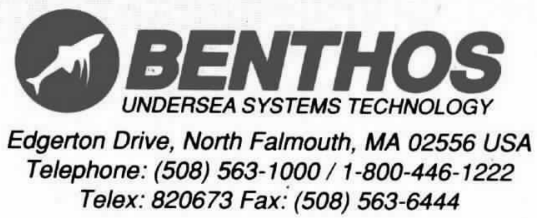

